\title{
Speech Functions Realized by the First Speakers of an English Debate Competition
}

\author{
Indriyati Hadiningrum \\ Department of English Language and Literature, Universitas Jenderal Soedirman \\ indriyati.hadiningrum@unsoed.ac.id
}

Article History:

First Received:

$04 / 06 / 2020$

Final Revision:

$28 / 06 / 2020$

Available online:

$30 / 06 / 2020$
Abstract. Debate is a form of argument or discussion of a particular issue and it usually involves two or more speakers who express different views from each other. In a debate, speakers produce meaningful string of words to express their opinions and the words they produce may contain speech functions. The focus of this study is the speech functions realized by the first speakers in a debate competition. The debate being studied refers to a competition called Indonesian Varsity English Debate (IVED), a national debate competition held in Universitas Jenderal Soedirman. The objectives of this study are to find out the speech function choices realized by both the first speakers of the affirmative and the negative teams; and to see how the use of speech functions contributes to the development of argumentation in the debate. The data was taken from an English debate competition, i.e. the final round of IVED, which was recorded on a video compact disk. The qualitative method was conducted, and the speech functions were categorized based on the network of speech function developed by Suzanne Eggins and Diana Slade (1997). The results of this study show that the speech functions realized by the first speaker of the affirmative team are opening and continuing speech functions. The speakers of the negative team, by contrast, realized opening, continuing, and reacting speech functions because they needed to issue rebuttals of the affirmative arguments.

Keywords: speech functions, debate, argument,

\section{http://jos.unsoed.ac.id/index.php/jes}

\section{INTRODUCTION}

Debate can be defined as a discussion when speakers present arguments to persuade an audience or interlocutors. In a debate competition, participants in a debate, or debaters, usually work in a team. They must think critically based on facts they have; so, they are able to defend their arguments.

Ericson et al (2003) state that debate occurs in every walk of life and relating to a formal debate they propose two basic rules: it presents one issue at a time and provides equal opportunity for presentation of each view point. On the other hand Meany and Kate Shuster (2003) highlight two characteristics of formal debates commonly have i.e., debates are usually on a fixed topic and participants in a debate try to persuade a third party (audience or judges). 
Based on the definitions, I try to summarize the characteristics of a debate. The context is generally formal focusing on a particular issue, and the arguments are well-organized. Besides, debate participants should be able to convince the other party that their arguments are right.

When debating, speakers or participants produce meaningful string of words expressing their ideas, arguments, and opinions. In this sense, speech sounds or voices are the medium, which in turn they are in the category of spoken language.

Seeing the phenomenon, I am interested in analyzing conversation in the form of a debate. I argue that debate is one form of conversation since it meets the condition for a conversation, i.e. there are speakers as well as hearers and also activities of exchanging meanings. Participants or speakers in a debate specifically present their arguments intended on persuading each other, using spoken language that is often supported by non-verbal activities, e.g. gesture and facial expressions.

When people participate in an interaction, they produce meanings that have been made in a particular context. It can be said that the fundamental purpose of language is to enable us to make meanings with each other as Eggins (1994: 11) explains that one reason why people interact is to make meanings that is to make sense of the world and of each other. On the other hand, Nofsinger (1991: 3-5) defines three primary characteristics of conversation: interactive, locally managed, and mundane. The first characteristic focuses on participants who exchange messages on a real-time basis. The second primary characteristic that is locally managed means that during an interaction, participants themselves determine which people get to speak, in what order they speak, and for how long. As the conversation progresses, this also includes the things people are expected to talk about, what they actually say, and how they say it. Then, the third important characteristic, mundane, means that conversation is commonplace and practical.

In contrast, Eggins (1994: 109) reveals two components of conversational structure: the choice of speech function and the type of exchange structure. The former relates to offer, command, statement, and question as the basic initiating speech functions. There are also responding speech functions to either support or confront the initiating ones; and they are accepting (an offer) vs. declining it, complying (with command) vs. refusing to comply, acknowledging or agreeing (with a statement) vs. disagreeing, and answering (a question) vs. disavowing.

The second component is about sequences of those speech functions that constitute jointly negotiated exchanges. Eggins (1991: 110) explains that "the minimal exchange is two speech functions (for example, offer + accept, or question + answer). However, she continues, exchanges can be of many moves, that is an exchange may include both preparatory moves and following-up moves which surround the core negotiation. Alternatively, there will be some exchanges that move directly to completion, while in other speakers make moves which delay or postpone the completion of the exchange structure.

Halliday, as cited by Eggins and Slade (1997: 181), displays the basic speech functions in the following table: 
Table 1. Speech roles and commodities in interaction

\begin{tabular}{lll}
\hline \multicolumn{1}{c}{ Speech role } & \multicolumn{2}{c}{ Commodity exchanged } \\
\hline Giving & Information & Goods-and-services \\
\hline Demanding & Statement & Offer \\
\hline
\end{tabular}

The table shows that if we are giving information, the speech function produced is 'statement'; and it is called 'question' if we are demanding information. Likewise, 'offer' is the result of giving goods-and-services; and if we are demanding goodsand-services, the speech function we produce is 'command'.

Moreover, Halliday (in Eggins and Slade, 1997: 182) also outlines the semantics of dialogue as presented below:

Table 2. Speech function pairs

\begin{tabular}{lll}
\hline Initiating speech function & \multicolumn{2}{c}{ Responding speech functions } \\
\hline & Supporting & confronting \\
\hline Offer & Acceptance & rejection \\
\hline Command & Compliance & refusal \\
\hline Statement & Acknowledgement & contradiction \\
\hline Question & Answer & disclaimer \\
\hline
\end{tabular}

From Table 2, it can be seen that supporting differs from confronting. Eggins and Slade (1997: 182) note that supporting responses enact consensus and agreement as well as tend to close off an exchange, as the proposition has been resolved. On the contrary, confronting responses enact disagreement or noncompliance and are followed by further negotiation, as respondents may either volunteer or are asked to provide justifications or explanations.

Then, Eggins and Slade (1997: 182) elaborate that the link between speech function and context is that the social role that participants are occupying in an interaction will constrain the speech functions they have access to when interacting with specific others. This relationship between social context and language as each speech function is associated with a typical mood structure as in the table below.

Table 3. Speech functions and typical mood in clause

\begin{tabular}{ll}
\hline \multicolumn{1}{c}{ Speech function } & Typical mood in clause \\
\hline Statement & Declarative \\
\hline Question & Interrogative \\
\hline Command & Imperative \\
\hline Offer & modulated interrogative \\
\hline Answer & elliptical declarative \\
\hline Acknowledgement & minor (or non-verbal) \\
\hline Accept & minor (or non-verbal) \\
\hline Compliance & minor (or non-verbal) \\
\hline
\end{tabular}


Eggins and Slade (1997: 191-192), then, present an overview of the speech function network that has been broken into four sections; they are opening speech functions, sustaining: continuing speech functions, sustaining: responding speech functions, and rejoinder speech functions. The explanation of the four sections is as follows:

1. Opening Speech Functions

As Eggins and Slade (1997: 194) state, the function of the opening is to initiate talk around a proposition. They are usually assertive moves to make, indicating a claim to a degree of control over the interaction. This occurs because the moves involve a speaker in proposing terms for the interaction. Table 4 below summarizes the speech function labels for opening moves.

Table 4. Speech function labels for opening moves

\begin{tabular}{|c|c|c|c|}
\hline Speech function & Discourse purpose & Congruent mood & Example \\
\hline Attending & Attention seeking & Minor; formulaic & Hey David! \\
\hline Offer & $\begin{array}{l}\text { Give goods and } \\
\text { services }\end{array}$ & $\begin{array}{l}\text { Modulated } \\
\text { interrogative }\end{array}$ & $\begin{array}{l}\text { Would you like } \\
\text { some more wine? }\end{array}$ \\
\hline Command & $\begin{array}{l}\text { Demand goods and } \\
\text { services }\end{array}$ & Imperative & Look. \\
\hline Statement: fact & $\begin{array}{ll}\text { Give } & \text { factual } \\
\text { information } & \end{array}$ & $\begin{array}{ll}\text { Full declarative; } & \text { no } \\
\text { modality; } & \text { no } \\
\text { appraisal } & \end{array}$ & You met his sister \\
\hline Statement: opinion & $\begin{array}{l}\text { Give } \\
\text { attitudinal/evaluative } \\
\text { information }\end{array}$ & $\begin{array}{l}\text { Full declarative; } \\
\text { modality and/or } \\
\text { appraising lexis }\end{array}$ & $\begin{array}{l}\text { This conversation } \\
\text { needs Allenby. }\end{array}$ \\
\hline Question:open:fact & $\begin{array}{ll}\text { Demand } & \text { factual } \\
\text { information } & \end{array}$ & $\begin{array}{l}\text { Wh-interrogative; } \\
\text { no modality; no } \\
\text { appraisal }\end{array}$ & $\begin{array}{l}\text { What's Allenby } \\
\text { doing these days? }\end{array}$ \\
\hline Question:closed:fact & $\begin{array}{l}\text { Demand confirmation } \\
\text { /agreement with } \\
\text { factual information }\end{array}$ & $\begin{array}{ll}\text { Polar } & \\
\text { interrogative; } & \text { no } \\
\text { modality; } & \text { no } \\
\text { appraisal } & \\
\end{array}$ & $\begin{array}{l}\text { Is Allenby living } \\
\text { in London now? }\end{array}$ \\
\hline Question:open:opinion & $\begin{array}{ll}\text { Demand } & \text { opinion } \\
\text { information } & \end{array}$ & $\begin{array}{l}\text { Wh-interrogative; } \\
\text { modality/appraisal }\end{array}$ & $\begin{array}{l}\text { What do we need } \\
\text { here? }\end{array}$ \\
\hline Question:closed:opinion & $\begin{array}{lr}\text { Demand } & \text { agreement } \\
\text { with } & \text { opinion } \\
\text { information } & \\
\end{array}$ & $\begin{array}{l}\text { Polar } \\
\text { interrogative; } \\
\text { modality/appraisal }\end{array}$ & $\begin{array}{l}\text { Do we need } \\
\text { Allenby in this } \\
\text { conversation? }\end{array}$ \\
\hline
\end{tabular}

2. Sustaining Speech Functions

Eggins and Slade (1997: 195) define sustaining moves as the moves to keep negotiating the same proposition. Sustaining moves remain "with" the Mood structure set up in an initiation. Moreover, they explain that sustaining talk may be achieved either as continuing speech functions, that is by the speaker who has just been talking or as reacting speech functions, that is by other speakers taking a turn.

There two main alternatives for a continuing speaker: to monitor or to prolong. Eggins and Slade (1997: 195-196) describe that when speakers monitor an 
interaction, they focus on the state of the interactive situation, for example by checking that the audience is following or by inviting another speaker to take the turn - this is set up as a supporting response. In other words, the monitoring moves occurred indicate an interest in deferring to or including other speakers and in seeking support for one's own position. The next option is to prolong where a continuing speaker adds to their contribution by providing further information. The function of prolonging moves, according to Eggins and Slade (1997: 198), is to enable speakers to flesh out their contributions, getting more than a single move in as speaker; and they frequently seem to pre-empt possible challenges or queries.

3. Reacting Speech Functions

Two segments of reacting speech functions are in this subtitle, i.e. responding and rejoinder moves. Eggins and Slade (1997: 200) explain that responses are reactions which move the exchange towards completion. These reactions negotiate a proposition or proposal on the terms set up by the previous speaker, and it means that the respondent accepts being positioned as a respondent and accepts to negotiate the other's proposition. Then, rejoinders, as written by Eggins and Slade (1997: 207), tend to set underway sequences of talk that interrupt, postpone, abort or suspend the initial speech function sequence. Thus, rejoinders either query it (demanding further details) or reject it (offering alternative explanations).

In analyzing speech functions, Halliday (in Eggins and Slade (1997: 185) suggests that the discourse patterns of speech function are expressed through moves. Moves are expressed in language through clauses. In this sense, moves are the discourse units, while clauses are the grammatical units.

Eggins and Slade (1997: 186) give two criteria for determining whether a clause is a move in a particular instance. They are the grammatical dependence or independence of the clause and the prosodic factors. The first criterion has three combinations: dependent clauses and the main clause on which they depend (e.g. If you're doing an Arts degree you got a lot of other garbage to do), embedded clauses (e.g. You met his sister that night we were doing the cutting and pasting up), and quoting or reporting clauses, both direct and indirect (e.g. I mean you've got to admit Roman is absolutely the cleanest guy in the flat). The second criterion, the prosodic factors, refers to clauses that express a complete tone contour (one at least) and that are frequently followed by brief or extended pauses. Eggins and Slade (1997: 188) explain that the identification of a move also depends on rhythm and intonation. This is because these systems interact with grammatical structure to signal points of possible turn transfer, i.e. move boundaries. This emerges a phenomenon of run-on where speakers can instead speed up, delay tone realization and rush on into the second or subsequent clause rather than breaking between clauses, slowing down and finalizing tone contour. Run-ons are as a single move since they are strategic manoeuvre which speakers use to try to avoid losing the turn.

I focus this study on the speech functions produced by the first speakers of an English debate, and the competition the writer analysed is the final round of the Indonesian Varsity English Debate (IVED). It was a national debate competition held at the University of Jenderal Soedirman in 2007. The first speakers' utterances are chosen because they are considered as the key speakers to make the second and third speakers able to develop the arguments. I try to find out the speech 
function choices used by the first speakers, both from the affirmative and the negative team. Then, I try to explain the use of the speech functions that contribute to the development of their arguments.

\section{RESEARCH METHOD}

The main data is the final round recording of the Indonesian Varsity English Debate (IVED) which is a national English debate competition held in Universitas Jenderal Soedirman in 2007. There were two teams, each representing affirmative (government) team and negative team. I watched and wrote the first speakers' speech in an orthographic transcription that is purposed to have valid and accurate analysis.

In order to obtain complete data, I wrote the transcription by playing and then replaying the VCD many times. Besides, I asked a colleague and two debaters to listen to the recording to compare my transcription.

In analyzing the data, I divided the written transcription into clauses as the first step. I analyzed the speech function based on the chart provided by Eggins and Slade. I numbered each clause produced by the first speakers, and then I classified the clauses based on the speech functions pairs suggested by Eggins and Slade (Table 2 above).

\section{RESULT AND DISCUSSION}

The debate competition being studied implements the Australasian Parliamentary debate system in which one team consists of three people. Each debater speaks in turn, and the affirmative team starts.

I will, first, highlight the summary of speech functions choices used by the first speakers of the debate. The first government speaker begins by introducing and defining the motion. S/he will set out affirmative's interpretation of the topic, express the team's opinion over the issue, and will also outline the team split. In contrast, the first speaker of the negative team will follow by identifying important matters they disagree, and s/he will rebut the major arguments stated by the government team.

The result shows that the first affirmative speaker only produced opening and continuing speech functions. The opening speech functions he produced are statement:fact and statement:opinion; whereas the continuing speech functions are monitoring and prolonging (elaborations, extension, enhancement). Then, the first negative speaker produced two opening speech functions, continuing speech functions (monitoring and prolonging); responding speech functions (developing, replying:supporting, confronting), and rejoinder speech functions (track, response:resolve, challenge).

Table 5 below presents the quantity of each speech function class

\begin{tabular}{|l|c|c|}
\hline \multirow{2}{*}{ Speech Functions } & Affirmative Team & Negative Team \\
\cline { 2 - 3 } & $1^{\text {st }}$ speaker & $1^{\text {st }}$ speaker \\
\hline Open & & \\
\hline Attending & - & 1 \\
\hline Offer & - & - \\
\hline Command & - & - \\
\hline
\end{tabular}


59 J-Lalite: Journal of English Studies Vol.1, No.1, June, 2020

\begin{tabular}{|l|c|c|}
\hline Statement:fact & 3 & - \\
\hline Statement:opinion & 1 & 1 \\
\hline Total & $\mathbf{4}$ & $\mathbf{2}$ \\
\hline Continue & & 10 \\
\hline Monitor & 22 & 4 \\
\hline Prolong:elaborate & 18 & 5 \\
\hline Prolong:extend & 17 & 2 \\
\hline Prolong:enhance & 15 & $\mathbf{2 2}$ \\
\hline Total & $\mathbf{7 3}$ & \\
\hline React:responding & & 13 \\
\hline Develop:elaborate & - & 9 \\
\hline Develop:extend & - & 3 \\
\hline Develop:enhance & - & 4 \\
\hline Replying:supporting & - & $\mathbf{3 4}$ \\
\hline Confronting & - & - \\
\hline Total & $\mathbf{0}$ & 2 \\
\hline React:rejoinder & & 1 \\
\hline Track:check & - & - \\
\hline Track:confirm & - & 3 \\
\hline Track:clarify & - & 3 \\
\hline Response:resolve & - & 7 \\
\hline Response:repair & - & 1 \\
\hline Challenge:rebound & - & \\
\hline Challenge:counter & - & \\
\hline Challenge:refute & - & \\
\hline Challenge:re-challenge & - & \\
\hline Total & $\mathbf{0}$ & \\
\hline & & \\
\hline & & \\
\hline
\end{tabular}

Table 5 gives information that the first speaker of the affirmative team made four opening speech functions and 73 continuing speech functions. He did not make any reacting speech functions because this relates to his role that he should begin the debate by introducing and defining the motion that was supported by arguments and evidence. This shows that the statements are categorized into opening by giving particular facts (explained below). On the other hand, the first speaker of the negative team made only two opening speech functions and made more continuing and reacting speech functions. This was because she needed to start to defeat the motion and refute the arguments of the government team, and this resulted in making more continuing speech functions (13 moves) followed by responding and rejoinder speech functions (11 and 13 moves respectively).

In IVED 2007, the motion of the debate in the final round was 'this house would change the electoral threshold from three percent to five percent minimum requirement'; and the affirmative team would defend the motion whereas the negative team would criticize or even disagree with it.

I found that the first government speaker opens the debate by directly giving factual information and opinion to start introducing the motion. The followings are the moves he produced: 
10 :statement:fact $\quad$ On the motion that this house would change the electoral threshold, ladies and gentlemen, in December two thousand and six researchers from UI recommended to the government to streamline the electoral threselectoral threshold, ladies and gentlemen.

2 0:statement:fact This result of the research was agreed by Partai Demokrat and also Golkar.

In move 1 above, the speaker directly stated the fact that there had been a recommendation to improve the electoral threshold, and it was agreed by two big parties (move 2). Furthermore, in move 3 he expressed an opinion on the negative reactions from small parties and another big party $(P D I P)$ that caused a conflict. Then, in the next move (4) he restated the motion as the fact of the debate.

3 0:statement:opinion But there was some negative reactions toward small parties and also PDIP as the formal opposition that we see this is the current conflict and the current issue in the development of democracy in Indonesia, ladies and gentlemen.

4 0:statement:fact What we are debating on today is that first of all what we need by elect- electoral threshold is we're gonna change it from the current three percent minimum requirement to a five percent minimum requirement.

The first affirmative speaker has identified the issue and has stated what his team understood about the topic. He has provided a noticeable introduction to the debate. In this case, he has also produced opening speech functions to give factual and evaluative information.

$\mathrm{He}$, then, defined it by initially saying the following statement:

7 P:enhance So our team, the affirmative, would be supporting the five percent increase in this minimum requirement for political parties whereas the negative team should say "we agree with status quo at three percent is enough", ladies and gentlemen.

He continued by monitoring and providing another enhancement as follows:

$8 \mathrm{C}$ :monitor Why do we want a five percent?

9 P:enhance We believe that is five percent will strengthen the symbol society of Indonesia through creating stability and empowerment, ladies and gentlemen.

It can be seen that in move 7 the affirmative speaker produced a continuing speech function which is enhancement. He explained the role the government and 
the negative teams would play; and afterwards in move 8 he addressed a question as a monitoring move in support of his argument. This is followed by enhancement as an explanation for the question (move 9). In addition, move 9 is also a prior statement for the speaker to develop the case approach, and in this case, he began with the 'why' aspect.

After that, to make a cogent argument for the motion, he split the case: one material was for him as the first speaker, and the other was as the second speaker's material. The split was shown in four moves as follows:

10 P:elaborate

12 P:enhance

13 P:enhance

14 P:enhance
First ... first I'll be explaining on the actual problems of political overlapping in ideology and how they ${ }^{* * *}$ ) fragments in political parties through three percent, ladies and gentlemen.

Second of all we say that if (the inherence is) we don't do anything, this fragmentation and this overlapping of idealism will continue, ladies and gentlemen.

Then our continuer will explain the development for the evolution of political democracy or the evolution of electoral threshold ladies and gentlemen.

My second speaker will be explaining to you how engagement in society would be better for political parties and how it will incr- increase the enhance the sense of democracy within the society, ladies and gentlemen.

Next, he outlined his arguments which were expressed in the moves below:

15 P:elaborate

16 P:extend
Onto the first point, ladies and gentlemen, the problems with the three percent, ladies and gentlemen.

The problems with the three percent is that there's a larger part of parties, ladies and gentlemen.

In his outline, the first affirmative speaker still produced the continuing speech functions i.e. prolonging moves: elaboration and extension. In his elaboration, he restated the information he had presented previously, and then he extended by giving additional information about the problem.

From this point, he developed the case and tried to prove his team's arguments. Hence, in the rest of his moves, he presented explanations as well as examples to support the arguments. He attempted to convince the audience that his arguments are reasonable. I figured out that he divided his arguments into two parts: first he described the problem with the three percent and then dealt with the parties' fragmentation.

In the first part of his argument, the speaker presented some examples and I observed that he tried to provide significant examples and the analysis as well, relating to the topic. The following is one case: 
23 C:monitor

24 P:elaborate

25 C:monitor

26 P:elaborate
Now what would be the examples of this state, ladies and gentlemen.

We have $P P P$ we have $P P P$ we have Bulan Bintang. We have all of these other Islamic parties, ladies and gentlemen.

Now, what is the foundation of these Islamic parties ladies and gentlemen?

Of course it's $\left(^{* * *}\right.$ ) in Indonesia, ladies and gentlemen.

In move 23 and 26 he produced monitoring moves to draw the audience's attention, and then he elaborated by giving the examples that were followed by the analysis. Even though I could not transcribe the full clause of move 26, I decide that this is the first government speaker's analysis based on the speech function production (P:elaborate) which is to exemplify the previous moves.

Likewise, the case below shows how the speaker attempted to defend his point of view by illustrating an example.

38 P:extend

39 P:elaborate

40 C:monitor

41 P:enhance

42 P:extend

43 P:extend

44 C:monitor

45 P:enhance

46 P:extend
It happens with $P K B$, ladies and gentlemen.

When there is ... one of the one the big counselor Gus Dur ( ${ }^{* * *}$ ) Hasyim Muzadi, ladies and gentlemen.

Now what is a problem in this, ladies and gentlemen?

Again, and again this type of problems or this fragmentation or this political orientation problem are not what the actual society wants, ladies and gentlemen.

And we said that this type of ... fragmentation and overlapping is not er er good democracy.

We say it's bad democracy.

Why ladies and gentlemen?

Because this is an illegal politics, ladies and gentlemen.

And it doesn't grasp the people of society of Indonesia, ladies and gentlemen.

The excerpt above shows that this time the speaker revealed a more extended analysis after giving the examples (move 38 and 39). The continuing speech functions shift around extension, elaboration, monitor, and enhancement. The extensions in move 42 and 43 were to give reasons as a continuance of move 41 while that in move 46 was an additional explanation to follow move 45.

In the second part of his argument, the speaker began with the 'how' aspect of the case approaches i.e. how this topic comes about.

48 P:extend

First of all the problem of overlapping to more and more parties, and second of all the problems of how more parties will become smaller and big 
parties will become even more smaller, ladies and gentlemen, $\left(^{* * *}\right)$ fragmentation, and we say that fragmentation in the society is not good.

In move 48 above, he actually drew a brief conclusion about the first part of his arguments, and then he introduced the second part of how an increase of five percent influenced the political situation in Indonesia. Thus the speech function was a continuing one because he continued his own explanation.

Following move 48, the first affirmative did not present any examples. He only made plausible arguments to support his analysis, and the production of speech functions was only continuing speech function (monitoring and prolonging).

65 C:monitor Now what about after thr- three percent, ladies and gentlemen.

66 C:monitor Will there be an improvement after this three percent increase in the electoral threshold?

67 P:elaborate And the answer was "yes", ladies and gentlemen.

68 P:extend And it was going to the five percent for the two

69 P:enhance thousand and nine.

So we see that there is the developing change, ladies and gentlemen, of the increasing number of of quota for the electoral threshold, ladies and gentlemen.

The speech functions he produced were just continuing speech functions that range between monitoring, enhancing, extending, and elaborating.

In fact, most speech functions produced by the first affirmative speaker are indeed continuing speech functions as shown in Table 5. This is because, as the main role of the first affirmative speaker, he only needs to focus on setting out his team interpretation of the motion by establishing their defense arguments.

Next, after some lines of arguments, the speaker should summarize and conclude his arguments, and this usually becomes an important part of the speech. However, in the data I collected, I found the first affirmative speaker did not really give a clear conclusion because he directly concluded after giving his explanation, like in move 69 above. Instead, he still tried to explain his other example, and this made him unable to reach a conclusion of his entire arguments. This was also because there was a final knock from the timekeeper, and as a result, he ended his speech somewhat in haste.

The next speech was from the first speaker of the negative team. As Quinn (2005: 94) suggested the duty of this speaker to give a brief introduction, rebutting the first affirmative speech, presenting the negative team's case approach, and explaining the team's split. Also, he needs to outline his argument and put forward the arguments, summarize them, and reach a certain conclusion. Moreover, Quinn also highlighted that the first negative speaker must deal with the affirmative team's definition either by agreeing or disagreeing with the government's definition.

The data shows that the first negative speaker initiated her speech with a brief introduction in two moves as follows: 
10 attending

The problem that is addresses by the government side of the house, ladies and gentlemen, is that how there are too many overlapping er overlapping parties in current condition and how they have actually have same ideology, but they actually split out and it's create confusion about people in current condition.

2 0:statement:opinion Now, those kinds of things are actually a just kind of assumption, ladies and gentlemen.

I am of the opinion that the first move is an opening:attending speech function. Although it is not in the form of salutations, greetings, or calls (as stated by Eggins and Slade), the function is similar that was to have the audience's attention. Then, before rebutting, she expressed her opinion about the affirmative's case approach (move 2).

The move indicating the initial rebut is move 3 when the first negative speaker disagreed with the affirmative's ideas.

3 R:confronting $\quad$ Because since the very first time, they actually ... there's such kind no problem, ladies and gentlemen.

Following the above move, the speaker produced reacting speech functions i.e. more responding moves than rejoinder and continuing moves. Most responding moves were to support the rejoinder moves, particularly when she defended her opinions against the affirmative team's arguments. She was attempting to challenge her opponent's definition and explain how the government's team definition was wrong.

She attacked by directly saying her disapproval; as follows:

14 R:confronting Now this is what ... the government of the house is actually neglected in this debate, ladies and gentlemen.

20 R:confronting Now those kinds of thing is neglected by government side of the house.

35 R:challenge: $\quad$ Because the first to the very first time their first rebound speaker even did not mention to you how this kind of things how by increasing electoral threshold to five percent it will increase the the government itself.

$36 \mathrm{R}$ :challenge:counter Now er me as the first speaker of (the opposition) of the house actually neglected their case in the very first place.

37 R:challenge: Now I will go on to my er first argumentation re-challenge and how we will show to you that in the current condition three percent of electoral threshold, ladies and gentlemen.

$53 \mathrm{R}$ :confronting Those kinds of thing neglected by the government side of the house. 
63 R:challenge:refute

72 R:challenge:counter

75 R:challenge:

re-challenge
Those kind of $(* * *)$ is actually neglected by the government.

So basically I have already neglected their problems on how there should such agency $(* * *)$ proving by their first speaker.

Now, we believe that their motion have already fallen in the first time.

The nine moves above indicate that the first negative strongly challenged the government's definition. The varied speech functions appeared because there were based on the details about how the affirmative's definitions were wrong. In moves 14 and 20 above the first negative confronted after explaining the reasons.

Whereas in moves 37 and 75 she re-challenged her opponent's definition, and I think she made such challenges to show that her explanations were more reasonable than the affirmative ones. This is especially when she presented the reasons after move 37 as follows:

42 R:s:affirm We're seeing that er this three percent of electoral threshold hamper the idealism, ladies and gentlemen.

43 R:D:enhance Because in current condition three percent of electoral threshold, ladies and gentlemen, we are seeing that in er in parliament there are er there are sec- there are ten parties there are ten fractions come from this kind of regulation.

Then, she continued her arguments in the following:

45 P:elaborate

46 P:extend

47 P:extend
We can see that our member of parliament can represent and can solve the problem of Indonesia well, ladies and gentlemen.

We are seeing how those kinds of many interest and many appreciations for the people have already accommodated in current condition, ladies and gentlemen.

We are seeing how this kind of things have already ideal to implement er implement three percent of electoral threshold.

I figured out that for the explanations, the speech functions were varied between reacting and continuing. This is because after rebutting, she explained the reasons and replaced the government's ideas with her own arguments. Hence, the responding moves (confronting) and the rejoinder moves (rebound, counter, rechallenge), in this case, were positioned as triggers to elaborate the attacks as shown in the excerpt below:

67 R:challenge:counter

And second of all how we do believe that their mechanism will only worsening the condition, hampering the access of democracy in this current condition. 
68 R:D:enhance

69 C:monitor

70 P:elaborate

71 P:extend
Because they believe that only minority ... only majority parties that can involve.

What will happen?

It will created monopoly of this kind majority parties and minority parties will not involve in er in the policy making decisions.

And what will happen is actually hampering the (union) of Indonesia in the sense of democracy.

I also found that the first negative speaker had the same opinion as the affirmative's in that electoral threshold is needed in all countries as can be found in move 40 below:

40 R:agree

Now we er we do agree that electoral threshold is actually needed, ladies and gentlemen, in all countries.

41 R:disagree

But we see that there's no (so urgency) to increase with their mechanism.

However, she immediately disapproved (move 41) that there was no need to improve the system (according to the motion, this was the situation in Indonesia). This is in line with what Quinn suggested that the first negative stated her disagreement with the affirmative's definition in only one short sentence and then it was continued with rebuttal.

Similar to the role of the first affirmative speaker, the first negative speaker should also draw conclusion of the arguments. The conclusion contained reacting speech functions and one continuing speech function.

72 R:challenge:counter So basically I have already neglected their problems on how there should such agency ${ }^{* * *}$ ) proving by their first speaker.

73 R:D:extend

There is no such tangible how people confusing and at the end hampering the access of democracy.

74 R:challenge:counter And second of all I've already proved to you that their mechanism will only worsening condition of there is reduce of voices.

75 R:challenge: Now, we believe that their motion have already re-challenge fallen in the first time.

I found that she reached a more explicit conclusion than that drawn by the first government speaker. She clearly stated that the arguments she presented had proved that the problems addressed by the affirmative were not resolved.

\section{CONCLUSION}

The first speakers play an important role in bringing their team to have strong arguments. The opening and continuing speech functions they produced have led them to develop and then win their arguments. They can still elaborate and agree/disagree with their opponent's arguments. 
Compared to the first affirmative speaker who does not produce reacting speech functions, the first negative speaker produced reacting speech functions because he must issue a rebuttal of the first affirmative's arguments. The speech functions found in this study may contribute to the development of argumentation in a debate in that they are seen as a pattern of giving opinions or arguing about given issues.

\section{REFERENCES}

Branham, Robert and John Meany. 1998. Parliamentary Debate. An article from http://debate.uvm.edu/meanyparli.html.

D'Cruz, Ray. 2003. The Australia-Asia Debating Guide. An online publication by the Australian Debating Federation.

Eggins, S. (1994). An Introduction to Systemic Functional Linguictics. London: Printer Publishers Ltd.

Eggins, S. and D. Slade. (1997). Analyzing Casual Conversation. London: Cassel.

Ericson, Jon M., James J. Murphy, Raymond Bud Zeuschner. (2003). The Debater's Guide. An electronic publication on www.amazon.com. Accessed on June 2011.

Fiske, J. 1990. Introduction to Communication Studies. London: Routledge.

Meany, John and Kate Shuster. (2003). On That Point: An Introduction to Parliamentary Debate. An electronic publication on www.amazon.com. Accessed on June 2011.

Miles, M.B. and A.M. Huberman. 1984. Qualitatives Data Analysis: A sourcebook of New Methods. California: Sage Publications, Inc.

Nofsinger, Robert E. (1991). Everyday Conversation. Illinois: Waveland Press, Inc.

Quinn, Simon. (2005). Debating. An electronic publication on www.learningdebating.com

Silverman, David. 2000. Doing Qualitative Research: A Practical Handbook. London: SAGE Publications Ltd. 